\title{
School Management Application Using iOS
}

\author{
Renas Rajab Asaad ${ }^{1}$, Rasan Ismail Segerey ${ }^{2}$
}

Department of Computer Science, Nawroz University, Duhok, Kurdistan Region - Iraq, Researcher, Duhok, , Kurdistan Region - Iraq

\begin{abstract}
Recently, the mobile application become a big service that's make users easy manage the data over the server. The Application consist several sections. First section the Front End used is Swift Language in Xcode platform with MySQL and web server. Second section the Back End used is MySQL. In this paper there are several modules such as Data Entry module, Data Records module. These modules are further divided in to sub modules. That is Class Setup, Student Setup, Teacher Setup, Student Attendance, Subject Setup, Examination Setup and Exam Details are in Data Entry module. Student Details, Teacher Records, Student Attendance are in the Data Records module. These modules give way in managing the organization efficiently. So, this project helps in efficient management of human resource inside the organization. Also, it consumes less time consumption. The main and important benefit of this proposed Application is that it is very much user friendly and accurate. So the employees and the administrators feel so much comfortable to work with it. Also in all the modules the regularly updated information are very much useful when they are extracted.
\end{abstract}

Keywords: iOS, School Management Application, Computer Science.

\section{Introduction}

A School Management Application is a large database application which can be used for managing school's daily work. It is configurable and can be configured to meet most individual school's needs. It is a multi-user application and can be used by hundreds of users at same time. General speaking, it is platform running Online through internet and is connected to online database and server.(Wei-Meng Lee 2014).

\section{LITERATURE REVIEW}

School management application online or web based school management tool is an integrated solution meant for bringing better management in the school premises and provide higher quality education to students. you need to take a look at its functionality and features to grasp why on-line school management apps.(Wei-Meng Lee 2014). And also, for attractive future with modern technologies on all education fields between student, teachers, family, and community.

Academic Journal of Nawroz University

(AJNU) Volume 7, No 4 (2018).

Regular research paper: Published 21 December 2018

Corresponding author's e-mail : renas_rekany@yahoo.com

Copyright @2017 Renas Rajab Asaad, Rasan Ismael Segerey.

This is an open access article distributed under the Creative

Commons Attribution License.

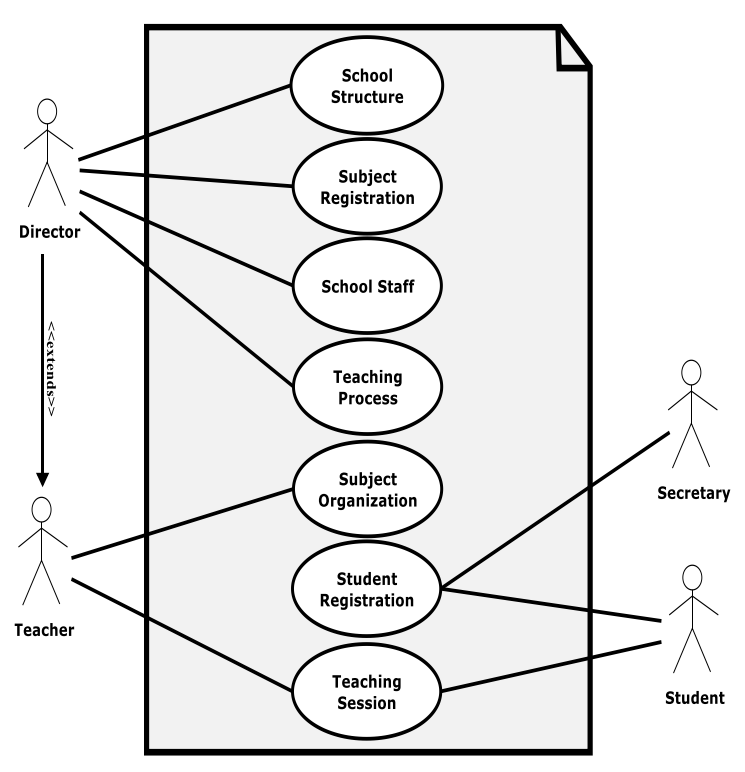

Fig 1. School Management 


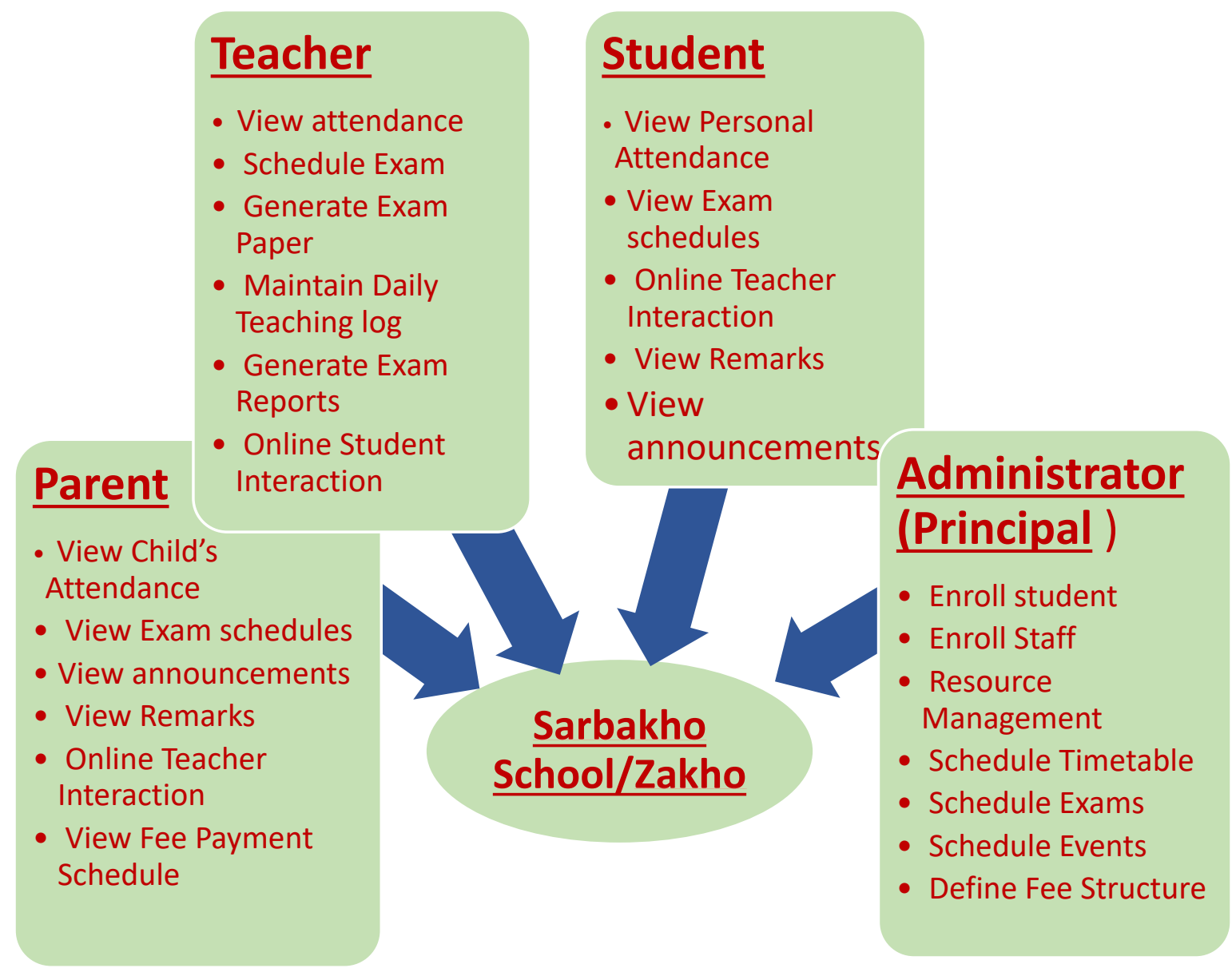

Fig 2. School Application

\subsection{App's Environment}

Three levels of users with different rights upon the data/information that can be stored, retrieved or modified: (Manager, Teachers, Students).

\subsection{Objectives}

The main objective at the end of the day for any school is the dissemination of information in an environment that encourages accountability, relevance and retention of the information gathered. Such are the main objectives of a school administrator, who, as a student manager, is charged with allowing this opportunity and environment to occur on behalf of the students. Here are some of the goals and roles of student management:

- Creation of Classroom Instructional resources.

- The Development of Academic related programs.

- Monitor the progress of the students in academic matters.

- Teacher management and resource.

- Career Counseling.

- Administration, Records and Accountability.
- Supervision of Teachers and School administrators, and Student Support officials.

- Create Contact Point for Parents.

- School finance management.

\subsection{Objective-C}

Objective-C is a general-purpose, object-oriented programming language that adds Smalltalk-style messaging to the $\mathrm{C}$ programming language. (Wikipedia.org). It was the main programming language used by Apple for the OS X and iOS operating systems, and their respective application programming interfaces (APIs) Cocoa and Cocoa Touch prior to the introduction of Swift. The programming language Objective-C was originally developed in the early 1980s. It was selected as the main language used by NeXT for its NeXTSTEP operating system, from which OS $\mathrm{X}$ and iOS are derived. Portable Objective-C programs that do not use the Cocoa or Cocoa Touch libraries, or those using parts that may be ported or reimplemented for other systems, can also be compiled for any system 
supported by GNU Compiler Collection (GCC) or Clang.(Stephen G. Kochan 2012).

\subsection{Xcode IDE}

Xcode is the complete developer toolset used to create apps for Apple TV, Apple Watch, iPad, iPhone, and Mac. The Xcode development environment bundles the Instruments analysis tool, Simulator, and the OS frameworks in the form of tvOS SDKs, watchOS SDKs, iOS SDKs, and macOS SDKs.

The integrated development environment (IDE) from Apple that is used to create, compile and test Mac OS $X$ and iOS (iPhone/iPad/iPod) applications. Introduced with OS X Version 10.3 (Panther) and evolving from Apple's Project Builder, Xcode supports writing in C, C++, Objective-C, Swift, AppleScript, Java and Cocoa. See Mac OS X, Objective-C and Cocoa. (Wei-Meng Lee 2014).

\subsection{Swift Programming Language}

Swift is Apple's new language option for programming native iOS applications. It complements Objective-C, and this will be the case for some time, now at version 2 , there is no better time to learn the new language.

Objective-C developers will find a lot of similarities with additional features such as type inference, strong typing, no reliance on header files, generics and more. In this tutorial I will show you how to get started developing iOS applications with Swift 4.0 will show how to setup a development environment, look into language fundamentals and compare the syntax with Objective-C, JavaScript and C\#. At the end of this tutorial you will have created a simple but complete iOS application using Swift. There are many cases when Objective-C, C\# and Swift share similar syntax, refer to this file for a complete reference.

\subsection{Web-Hosting}

Web hosting is a service that allows organizations and individuals to post a website or web page onto the Internet. A web host, or web hosting service provider, is a business that provides the technologies and services needed for the website or webpage to be viewed in the Internet. Websites are hosted, or stored, on special computers called servers.

When Internet users want to view your website, all they need to do is type your website address or domain into their browser. Their computer will then connect to your server and your webpages will be delivered to them through the browser. (website.com).

Most hosting companies require that you own your domain in order to host with them. If you do not have a domain, the hosting companies will help you purchase one.

There are various types of web hosting services available to host your website. Before signing up for web hosting services, it is important to understand what kind of service your website needs, the kind of server you or your business needs, your budget, and what type of services the web host offers.

Hosting options available are:
- Website Builders
- Shared Hosting
a Dedicated Hosting
- Collocated Hosting
- Website Builders

Website builder services is a type of hosting service that caters to beginners who need to host a website, but lack the technical skills and knowledge to build one. Website builder services typically provide you with an online browser-based interface to build your website, and also host the website for you without any additional setup. (website.com)

- Shared Hosting

- Dedicated Hosting

- Collocated Hosting

- Domain Name Server (DNS)

\subsubsection{WebHost}

A hostname is the label (the name) assigned to a device (a host) on a network and is used to distinguish one device from another on a specific network or over the internet.

The hostname for a computer on a home network may be something like new laptop, Guest-Desktop, or FamilyPC. Hostnames are also used by DNS servers so you can access a website by a common, easy-toremember name to avoid having to remember a string of numbers (an IP address) just to open a website. For example, in the URL pcsupport.about.com, the hostname is PC support. More examples are shown below.(website.com)

A computer's hostname may instead be referred to as a computer name, site name, or node name. You may also see hostname spelled as host name.

\subsubsection{MySQL}

MySQL, the most popular Open Source SQL database management system, is developed, distributed, and supported by Oracle Corporation.

The MySQL website (http://www.mysql.com/) provides the latest information about MySQL software. (Mathew Stucky 2001).

- MySQL is a database management system.

- MySQL databases are relational. 
- MySQL software is Open Source.

- The MySQL Database Server is very fast, reliable, scalable, and easy to use.

- MySQL Server works in client/server or embedded systems.

- A large amount of contributed MySQL software is available.

\subsubsection{PhpMyAdmin}

phpMyAdmin is a free software tool written in PHP, intended to handle the administration of MySQL over the Web. (php.com) phpMyAdmin supports a wide range of operations on MySQL and MariaDB. Frequently used operations (managing databases, tables, columns, relations, indexes, users, permissions, etc) can be performed via the user interface, while you still have the ability to directly execute any SQL statement. (phpmyadmin.net).

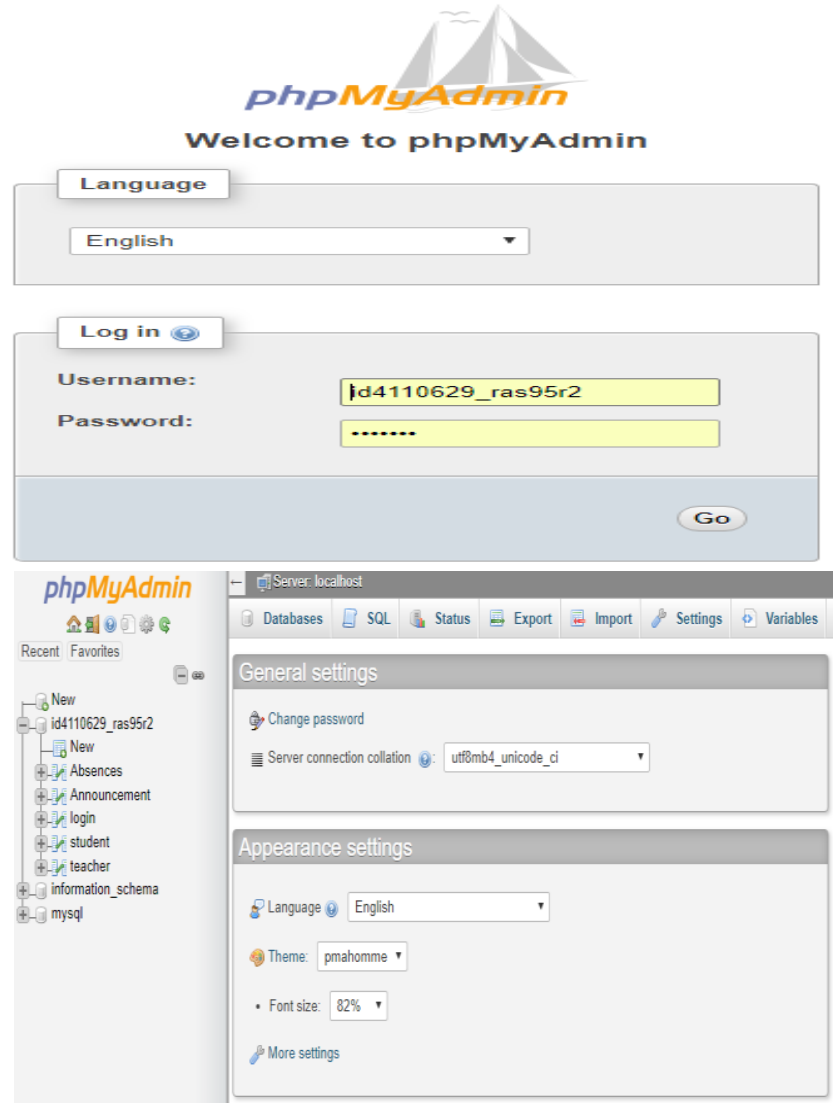

Fig 3. phpMyAdmin

\section{Implementation And Design}

School Management Application has three basic levels will be discussed in this chapter that is contain as mentioned before (Manager, Teacher and Students). This application created by Xcode "Swift" programming on iOS operating system. This chapter will discuss the environment of project and the implementation of it. (Apple Inc 2017).

\subsection{View Controller}

The Role of View Controllers. View controllers are the foundation of your app's internal structure. Every app has at least one view controller, and most apps have several. Each view controller manages a portion of your app's user interface as well as the interactions between that interface and the underlying data. (Apple Inc 2017).

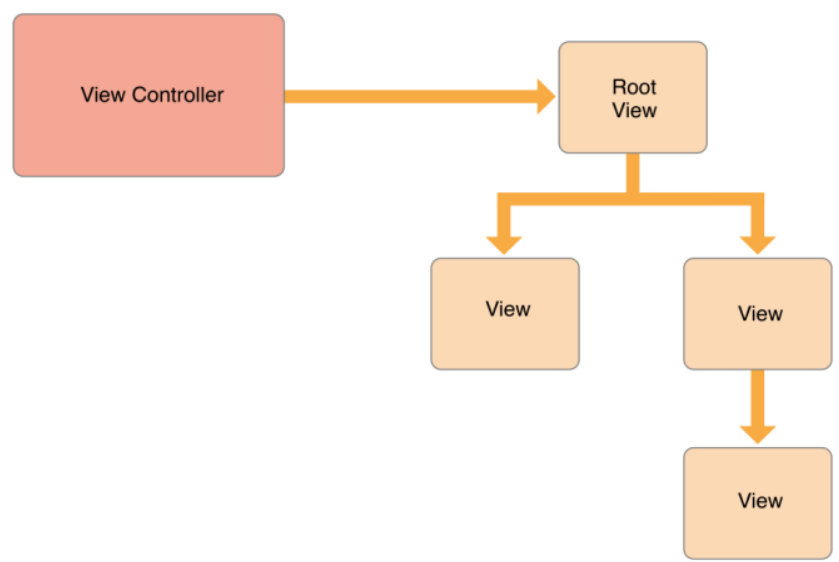

Fig 4. Relationship Between a View Controllers

\subsubsection{Login and Main View}

The first view in the application is start with login view, then goes to main view, the application contains four basic sections Manager, Teacher, Students and About view as shown bellow:

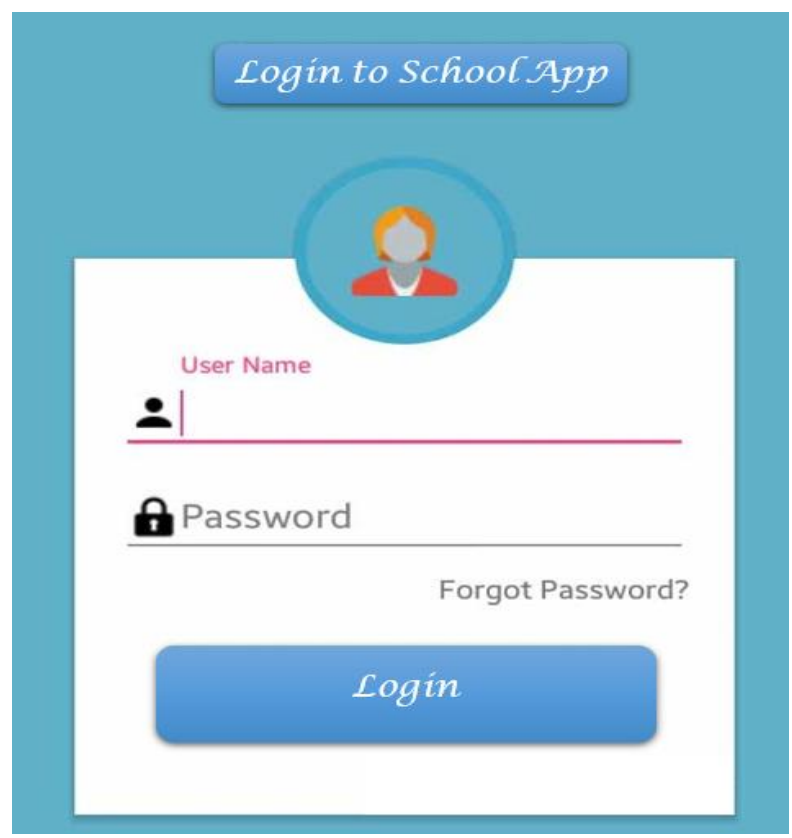

Fig 5a. Login View 


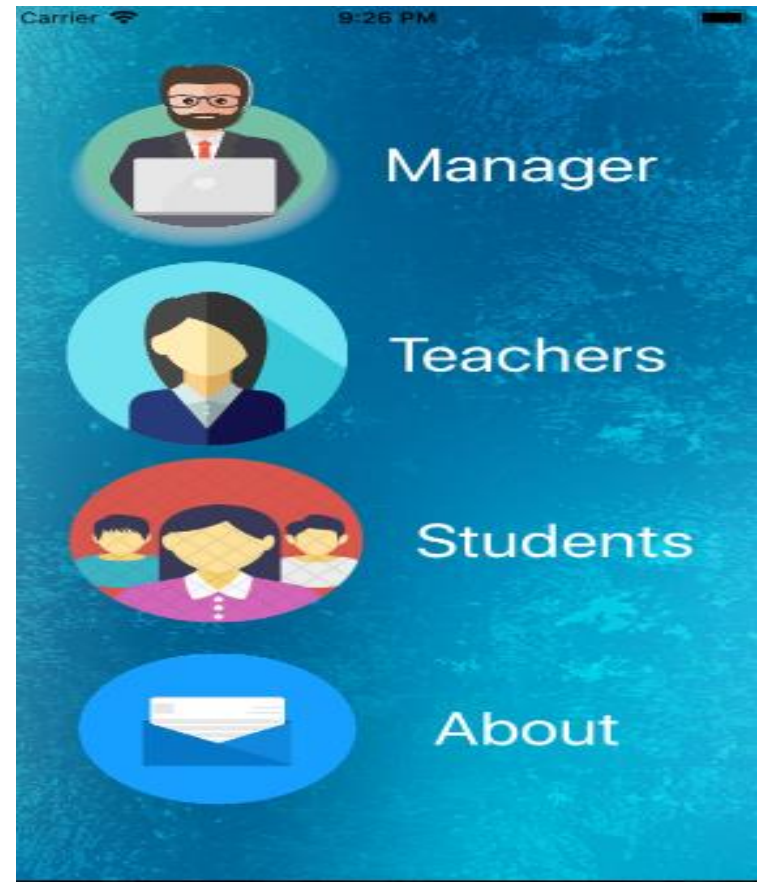

Fig 5b. Main View

\subsubsection{Manager View}

This view to manage the students information, teachers information, announcement, attendance, degrees, schedules as shown bellow:

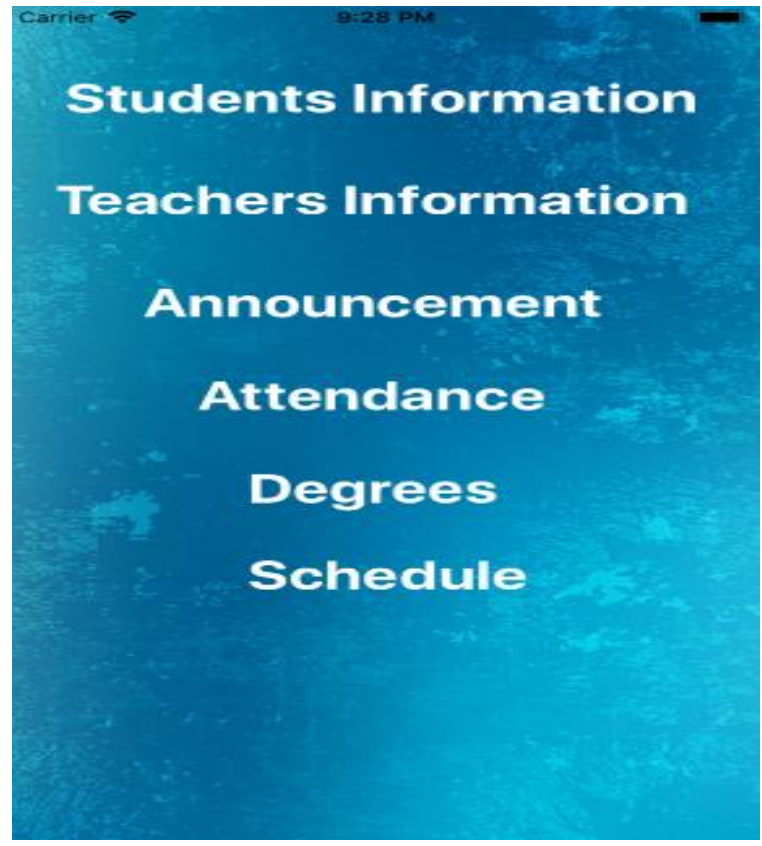

Fig 6. Manager View

\subsubsection{Teachers and Students View}

This view allow the teacher to insert announcement and attendance as shown bellow, also allow teachers to display the information about students in other views.

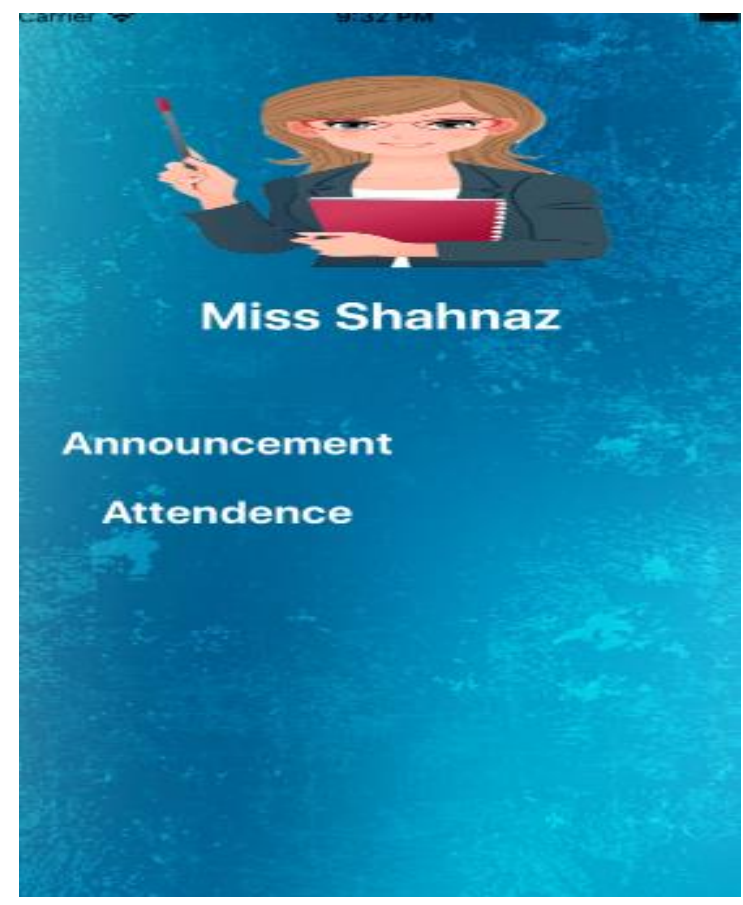

Fig 7. Teacher and Students View

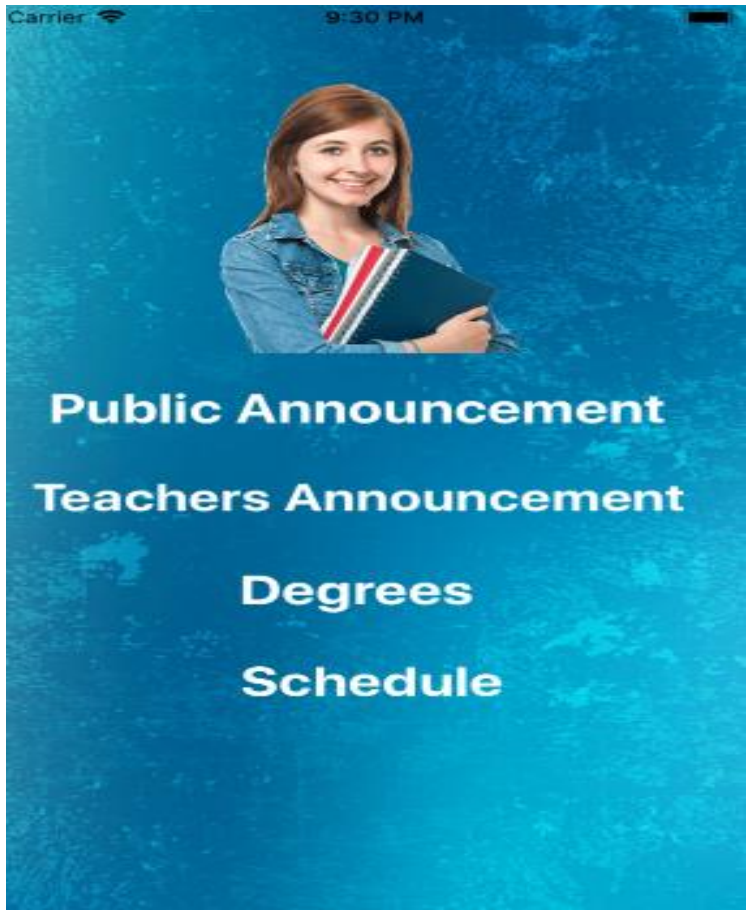

Fig 7. Teacher and Students View 


\subsubsection{Attendance View}

This views to display the attendance and allowing inserting it as shown bellow:

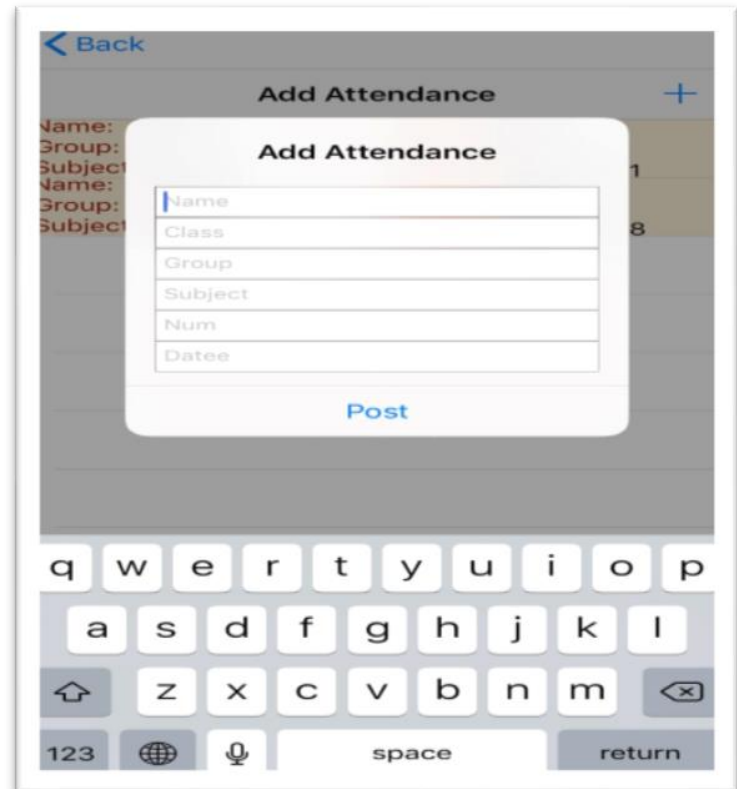

Fig 8. Attendance View

\subsubsection{Degrees and Schedules View}

Bellow view to display students degrees as a pdf extension.
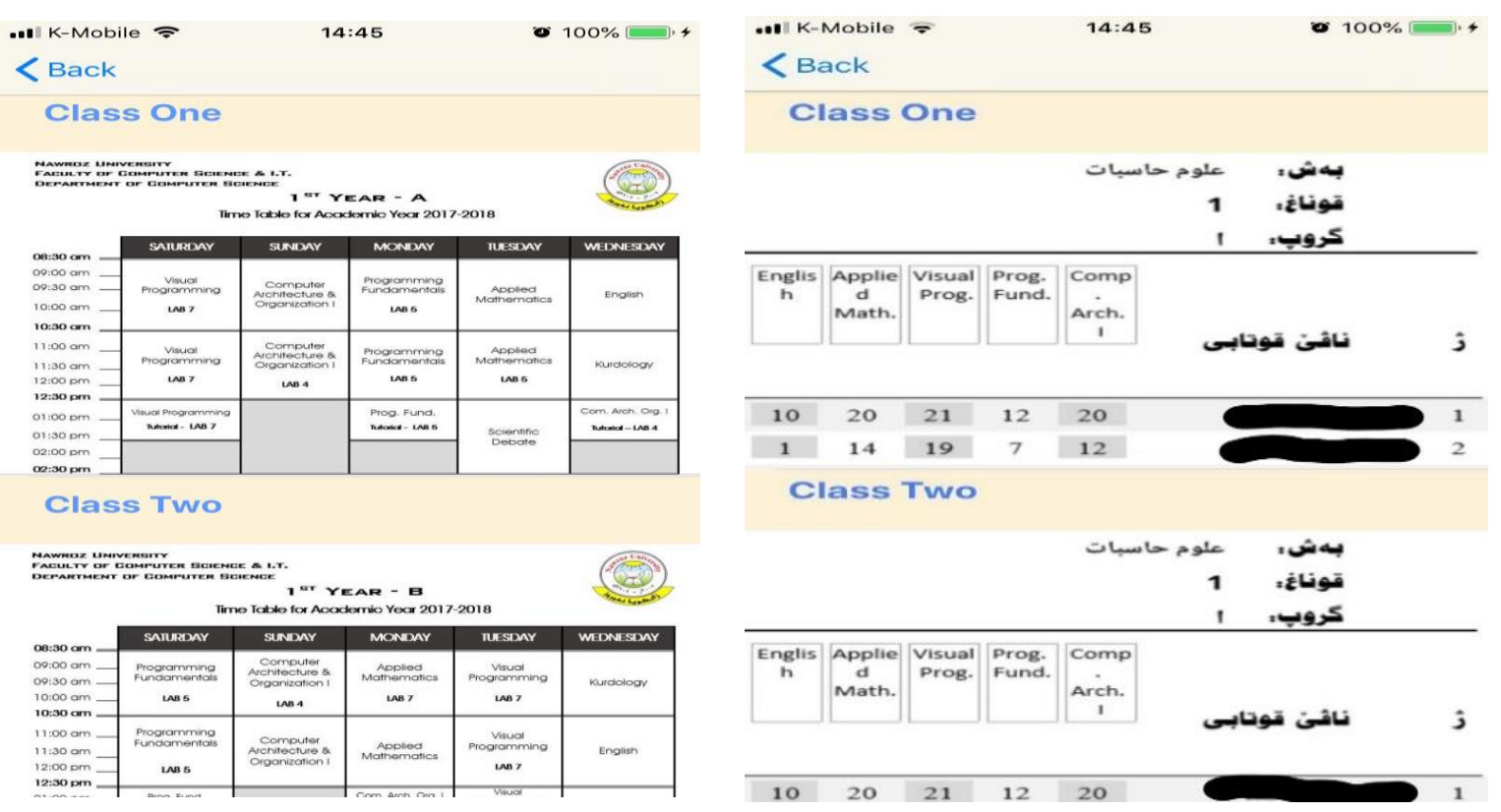

Fig 9. Degrees and Schedules View 


\subsubsection{Students Information View}

Bellow views to display information about students and adding a new one.

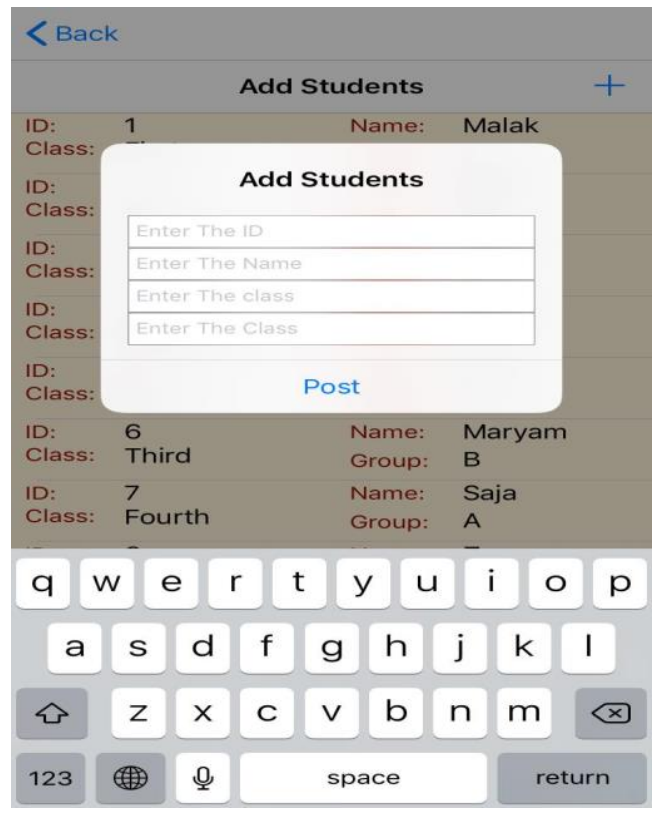

\begin{tabular}{llll} 
L Back & & \\
& \multicolumn{3}{c}{ Add Students } \\
\hline ID: & 1 & Name: & Malak \\
Class: & First & Group: & A \\
ID: & 2 & Name: & Alaa \\
Class: & First & Group: & B \\
ID: & 3 & Name: & Asala \\
Class: & Second & Group: & A \\
ID: & 4 & Name: & Solin \\
Class: & Second & Group: & B \\
ID: & 5 & Name: & Ayat \\
Class: & Third & Group: & A \\
ID: & 6 & Name: & Maryam \\
Class: & Third & Group: & B \\
ID: & 7 & Name: & Saja \\
Class: & Fourth & Group: & A \\
ID: & 8 & Name: & Zena \\
Class: & Fourth & Group: & B \\
ID: & 9 & Name: & Shams \\
Class: & Fifth & Group: & A \\
ID: & 10 & Name: & Broj \\
Class: & Fifth & Group: & B \\
ID: & 11 & Name: & Israa \\
Class: & Sixth & Group: & A \\
ID: & 12 & Name: & Nahla \\
\hline
\end{tabular}

Fig 10. Student Information View

\subsubsection{Announcements View}

In this view the manager and teachers can add a new announcement as shown bellow:

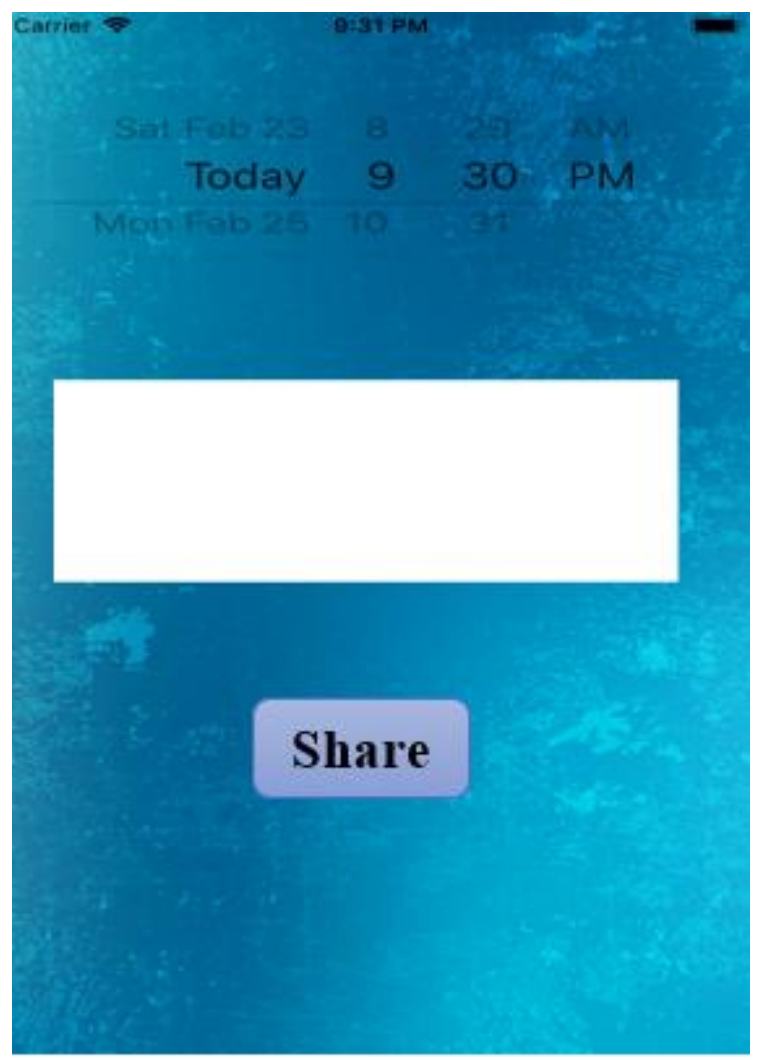

Fig 11. Announcements View

\section{Data \& Mark Analasis Yearly}

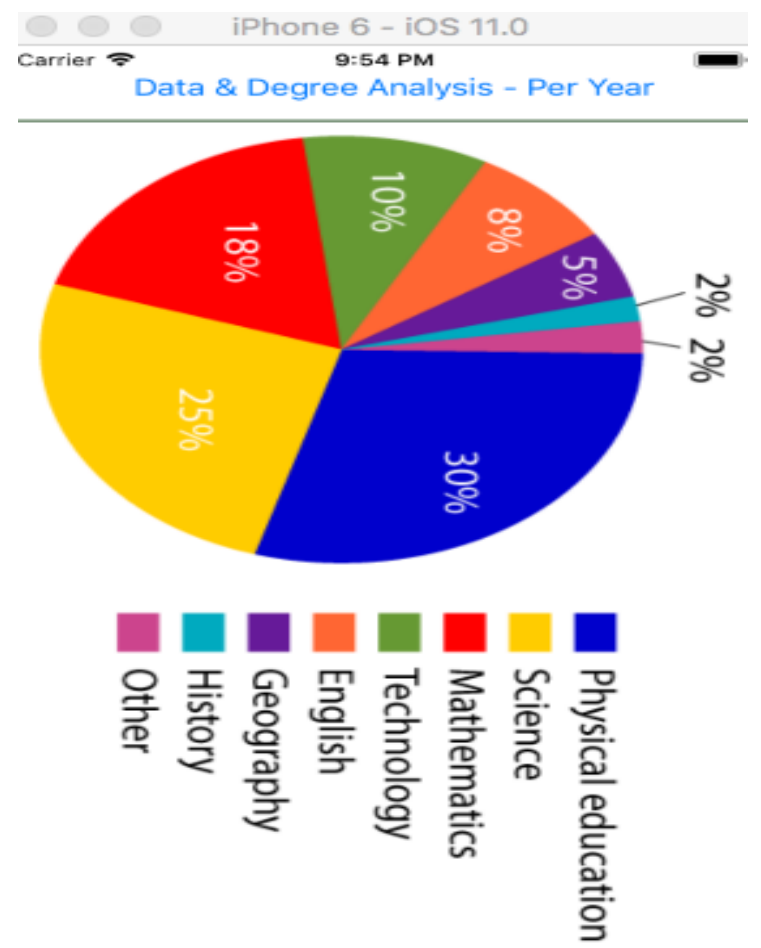

Fig 11. Announcements View

\section{Conclusions}

The main objective of this paper is to allow school's staff to easy manage the information's. The need of 
managing the information electronically is growing rapidly in all important areas in Kurdistan. School Management Applications are being identified as an appropriate method for managing information in schools. School Management Application was built based on real life situations in Kurdistan's high school, taking into consideration all possible situations and functionalities of the daily work in these schools. Also this Application maybe considered as a good first step in implementing performing electronic based information management in schools on iphone users using iOS operating system.

\section{REFERENCES}

Wei-Meng Lee, (2014) Beginning Swift Programming, Publishing, amazon.com;

Stephen G. Kochan; (2012) Programming in Objective$C$ fifth edition; Addison-wesley.

Apple Inc, (2017) The Swift Programming Language

(Swift 4): Swift is a fantastic way to write, Publishing, Wattanakarn Vladimirova.

Matthew Stucky, (2001) MySQL: Building User Interfaces, Mathew Stucky

www.mysql.com (Accessed Date 15/5/2018).

www.php.com (Accessed Date 15/5/2018).

https://en.wikipedia.org/wiki/Objective-C (Accessed Date 15/5/2018).

https://www.website.com/beginnerguide/webhosti ng/6/1/what-is-web-hosting?.ws (Accessed Date 15/5/2018).

https://dev.mysql.com/doc/refman/5.7/en/whatis-mysql.html (Accessed Date 15/5/2018).

https://www.phpmyadmin.net (Accessed Date 15/5/2018). 